although, in the course of a day, the pulse and respiration vary considerably; complains at times of pains in different parts of the body and abdomen; wound looks healthy, and urine passes freely.

29, Nine, p.m. Has had a restless night, and complains of tenderness of the abdomen, which is aggravated by a troublesome cough; is rather feverish, and appears weak and depressed; wound still looks well.

Ten, p.m. Fever has increased during the day, and tenderness of abdomen still continues; complains of flatulency, and there is slight tympanitis; pulse 123, small, and weak ; appears low and distressed, having an anxious, pinched expression of countenance. In the course of the day the wound has looked sluggish, and hot dressings have been applied. To have an ounce of wine every hour, and five grains of sesquicarbonate of ammonia, with one drachm of compound tincture of cardamoms, in an ounce of camphor mixture, every four hours; an opiate enema in the evening.

30. Since last night has gradually become weaker. Brandy and wine have been exhibited at frequent intervals, but with no benefit. He died at seven o'clock, a.m.

Sectio Cadaveris, Thirty Hours after Death.

The peritoneum contained a small quantity of seropurulent fluid, but presented no trace of active inflammation at any point. In the cul de sac, between the bladder and rectum, the surface was of a blue color, such as is the effect of putrefaction in warm weather. The surface of the wound, so far as it could be seen on looking from the perineum, was of an ash color. The rectum and bladder, with the skin and other tissues in the perineum, the symphysis pubis, and a portion of the penis, were removed. The fat and cellular tissue were cleared away, so as to permit a more accurate inspection of the parts in the vicinity of the neck of the bladder. Between the angle of the pubes and the latter part the textures seemed in a natural condition; there was no appearance of contusion, laceration, or infiltration of blood. Towards the right side of the prostate there was slight ecchymosis, but the external surface of this gland, on the left side, was in a natural condition. The cellular tissue between the bladder and rectum, and that lying on the outer surface of the gut, was softened and slightly infiltrated with a sero-purulent fluid. The softening appeared partly the result of inflammation, and partly of putrefaction. The side of the rectum next the opening into the bladder was of a blueish color, similar to that on the lower part of the peritoneum. The ureters (especially the left one) were larger than usual; they were traced into the bladder, and at these points, as well as in the site of the vesiculæ seminales, the bladder, although externally it seemed healthy, was somewhat thickened. The finger passed readily along the opening into the bladder, coming in its course into close contact with the rectum. The lateral lobes of the prostate were distinctly felt, the inferior and upper portions being by no means so perceptible as usual. The aperture here seemed like a vertical slit. The original opening into the urethra was at the back part of the bulb, and in this vicinity there were scarcely any traces of contusion. The interior of the bladder was exposed by a semilunar incision through the tunics on the left side. The mucous membrane presented no appearance of inflammation; it was, however, extensively sacculated, and several of the pouches were filled with concretions, some of them forming distinct elevations, about the size of peas, on the outer surface of the bladder. The membrane at these parts was remarkably thin. A close inspection of the neck of the bladder in the vicinity of the orifice detected slight marks of contusion, and here the surface of the opening appeared somewhat ragged, and it was apparent that the prostate had yielded chiefly in its lower part, and next in its upper. The wound was covered with shreds of lymph, and here the color was similar to that observed on the perineal end of the opening. A slit was made along the left side of the track, and the interior presented a rough lacerated surface, the mucous membrane of the urethra being nowhere visible, excepting at the upper part, where it was continuous with that in the sound portion of the tube. The kidneys were of a natural size, pale in color, and soft in texture. The right pelvis contained about eighteen or twenty small concretions, each about the size of a pin's head. The viscera of the abdomen generally healthy. No other region of the body was examined.-Lancet.

MEDICAL CHARITABLE SOCIETY OF THE WEST RIDING OF THE COUNTY OF YORK.

The fifteenth anniversary of this excellent institution was held at the Leeds School of Medicine on the 13th of July, 1843. It gives us much pleasure to perceive, from the report, that the society continues "to pursue its useful existence with energy and success."

The treasurer's account shows the income of the year to have amounted to $£ 7593 \mathrm{~d}$.

\section{ROYAL COLLEGE OF SURGEONS IN LONDON.}

Members admitted Friday, July 28, 1843.

W. Wilkinson, R. W. Watkins, E. J. Riccard, J. Palmer, H. Harding, E. Callender, H. Butler.

\section{TO CORRESPONDENTS.}

Communications have been received from $D r$. Woodkouse, Reading; from Mr. Copeman, Cottishall; from $M r$. Fletcher, Sheffield ; and from Mr. Terry, Northampton.

\section{ERRATUM.}

In Dr. Prichard's communication on transfusion of blood, an error of print has occurred, which we are desirous of correcting. The case should have been dated 1843, instead of 1834 .

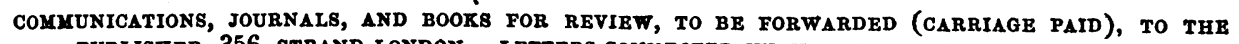
PUBLISHER, 356, STRAND LONDON. LETTERS CONNECTED WITH THE PBOVINCIAL ASSOCIATION, TO DR. STREETEN, WORCBSTBR. 